Rapid Reviews COVID-19

\title{
Reviews of "Protein arginylation is regulated during SARS-CoV-2 infection"
}

Fangliang Zhang ${ }^{1}$, Aaron Smith ${ }^{2}$

1"University of Miami Miller School of Medicine: University of Miami School of Medicine Pharmacology UNITED STATES",

2"Assistant Professor University of Maryland Baltimore County Chemistry and Biochemistry UNITED STATES "

Published on: Jan 26, 2022

License: Creative Commons Attribution 4.0 International License (CC-BY 4.0). 
To read the original manuscript, click the link above.

Summary of Reviews: This preprint looks at how SARS-CoV-2 infection modulates arginylation, a modification that tags proteins for degradation, and finds a specific arginylation signature in some cell types. The reviewers found the claims potentially informative.

\section{Reviewer 1 (Fangliang Zhang)}

\section{Reviewer 2 (Aaron Smith)}

\section{RR:C19 Strength of Evidence Scale Key}

$$
\begin{aligned}
& \text { प }
\end{aligned}
$$

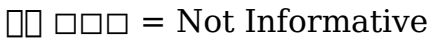

$$
\begin{aligned}
& \text { प्रा पर = Potentially Informative }
\end{aligned}
$$

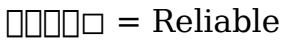

$$
\begin{aligned}
& \text { प्राप्र = Strong }
\end{aligned}
$$

To read the reviews, click the links below. 